REVISTA DE DERECHO UNED, NÚM. 18, 2016

\title{
EL DERECHO A INFORMAR DE LOS «PIQUETES» EN LAS HUELGAS Y SUS EXCESOS COACTIVOS
}

\section{THE RIGHT TO INFORM OF THE PICKETS DURING A STRIKES} AND THEIR COERCIVE EXCESSES

\author{
M. ${ }^{a}$ Isabel Serrano Maíllo \\ Prof. Derecho Constitucional \\ Universidad Complutense de Madrid
}

Resumen: Algunos grupos parlamentarios han pedido la derogación del artículo 315.3 del Código penal, referente a las coacciones llevadas a cabo por los piquetes durante las huelgas. En este trabajo se analiza brevemente dicho artículo y las consecuencias que tendría su derogación.

Abstract: Some parliamentary groups have called for the repeal of section 315.3 of the Criminal Code, concerning on the coactive actions carried out by picketing during strikes. In this paper we'll review that article and the consequences of repeal.

Palabras clave: derecho a la huelga, piquetes coactivos, piquetes informativos, delito de coacciones, derecho a la información.

Keywords: right to strike, coercitive pickets, informative pickets, crime of coercion, freedom of speech.

Recepción original: 23/02/2016

Aceptación original: 06/04/2016

El derecho a la huelga viene ocupando, en los últimos tiempos un lugar protagonista en los medios de comunicación a causa del apoyo 
que algunos políticos ${ }^{1}$ han prestado a los ocho trabajadores de Airbus que participaron en un piquete durante la huelga general de septiembre de 2010. Estaban acusados de emplear la violencia para conseguir sus objetivos, es decir, de formar parte de un piquete coactivo y no de uno informativo ${ }^{2}$, único tipo de piquete permitido por la ley. El juicio tuvo lugar durante el pasado mes de febrero y los trabajadores fueron finalmente absueltos por falta de pruebas ${ }^{3}$. El foco informativo se produjo, sobre todo, por la aparición en escena de políticos como Sánchez e Iglesias ${ }^{4}$, quienes han aprovechado este hecho para solicitar que se derogue el art. 315.3 del Código penal, al que nos referiremos más adelante.

El derecho a la huelga, como sabemos, se reconoce en el artículo 28.2 de la Constitución Española, como medio para defender los intereses laborales de los trabajadores ${ }^{5}$. Este derecho incluye la posibilidad de que los trabajadores informen a sus compañeros o traten de disuadirlos de que acudan a su puesto de trabajo, como reconoce el Tribunal Constitucional en su sentencia 137/1997, de 27 de julio, en la que recoge que «La actividad del llamado piquete de huelguistas con sus funciones de información, propaganda, persuasión a los demás trabajadores para que se sumen a la huelga o disuasión a los que han optado por continuar el trabajo, integra pues el contenido del derecho reconocido en el art. 28.2 CE» (FJ 3). Esta función informativa también queda regulada en el artículo 6.6 del Real Decreto 17/1977, de 4 de marzo, sobre relaciones de Trabajo, donde se dice que «Los trabajadores en huelga podrán efectuar publicidad de la misma, en forma pacífica y llevar a efecto recogida de fondos sin coacción alguna». Sin embargo, dicha función de información no incluye la coacción ni la violencia contra aquellos otros trabajadores que legítimamente de-

${ }^{1}$ El País, 09/02/2016: «Los "ocho de Airbus" se sientan en el banquillo arropados por sindicatos y políticos». http://economia.elpais.com/economia/2016/02/09/actualidad/1455008620_231709.html

${ }^{2}$ DÍEZ PICAZO, L.: Sistema de derechos fundamentales, pág. 500, dice: «Igualmente atentatoria contra la libertad de cada trabajador (...), es la violencia que a veces ejercen los piquetes: la existencia de piquetes es perfectamente lícita, pues sin ellos no habría huelgas; pero el uso de medios violentos por los mismos es siempre ilícito». Civitas, 2005, Madrid.

${ }^{3}$ El Mundo, 17/02/2016: «Absueltos 'los 8 de Airbus' por falta de pruebas» http:// www.elmundo.es/economia/2016/02/17/56c44e7e22601d11078b45bc.html

${ }^{4}$ El Mundo 09/02/2016: «Sánchez e Iglesias salen en apoyo a los «ocho de Airbus», acusados por un delito de "coacción a la huelga»

(http://www.elmundo.es/economia/2016/02/09/56b9cbcdca474174328b458e.html)

${ }^{5}$ Art. $28.2 \mathrm{CE}$ : «Se reconoce el derecho a la huelga de los trabajadores para la defensa de sus intereses. La ley que regule el ejercicio de este derecho establecerá las garantías precisas para asegurar el mantenimiento de los servicios esenciales de la comunidad.» 
sean acceder a su puesto trabajo. Y esto porque como recuerda el Tribunal Constitucional, esa conducta afectaría «a otros bienes o derechos constitucionalmente protegidos, como la libertad de trabajar o la dignidad de la persona y su derecho a la integridad moral que plasman los arts. 10.1 y 15 C. E.» ${ }^{6}$.

Hasta el Código Penal de 1995, estas conductas -las de los piquetes coactivos- se consideraban coacciones agravadas ${ }^{7}$, pero en el nuevo código se introdujo un tipo de coacción específico referido a la huelga, recogido en el art. 315.3 del Código penal, donde se dice: "Quienes actuando en grupo o individualmente, pero de acuerdo con otros, coaccionen a otras personas a iniciar o continuar una huelga, serán castigados con la pena de prisión de un año y nueve meses hasta tres años o con la pena de multa de dieciocho meses a veinticuatro meses.» Así pues, en caso de que las coacciones sean ejercidas durante una huelga con el fin que recoge la norma, se aplicará el artículo 315.3 del Código penal, por ser ley especial y, por tanto, de aplicación preferente frente a las coacciones comunes ${ }^{8}$. Hay que advertir, no obstante, que este tipo penal no es una novedad, sino que existen precedentes en códigos anteriores ${ }^{9}$, como en el de $1928^{10}$ y la reforma de $1976^{11}$.

${ }^{6}$ STC 137/1997, de 27 de julio (FJ.3).

${ }^{7}$ Vid infra nota 11.

${ }^{8}$ En principio la pena prevista en el artículo $172.1 \mathrm{CP}$ es prisión de seis meses a tres años o con multa de 12 a 24 meses. En el artículo $315.3 \mathrm{CP}$ es "prisión de un año y nueve meses hasta tres años o con la pena de multa de dieciocho meses a veinticuatro meses». En la reforma del Código penal de marzo de 2015 se suaviza la pena, pues con anterioridad la prisión podía llegar hasta cuatro años y seis meses. Antes de la reforma junto a la pena de prisión había también pena de multa, ahora la pena es alternativa, prisión o multa.

${ }^{9}$ En la nueva incorporación del delito al Código en 1976 se contemplaba como un supuesto agravado dentro del capítulo dedicado a las «amenazas y coacciones», en el Título XX del Libro II, que rezaba bajo la rúbrica: «De los delitos contra la libertad y seguridad». En el Código de 1995 pasan al Tít. XV «De los delitos contra los derechos de los trabajadores».

${ }^{10}$ Dentro del Capítulo dedicado a las " amenazas y coacciones» establecía en su art. 677:«Los que para formar, mantener o impedir las coligaciones patronales u obreras, las huelgas de obreros o los paros de patronos, o con ocasión de una u otras, emplearen la violencia, fuerza o intimidación para forzar el ánimo de obreros o patronos en el ejercicio legítimo y libre de su trabajo o industria o les obligaren a realizar actos favorables o contrarios a la huelga... serán castigados con la penas de tres meses a un año de prisión y multa de 1.000 a 2.500 pesetas...»Vid. también arts. 678 y 679 .

${ }^{11}$ Ley 23/1976, de 19 de julio. Dentro de cap. VII del Tít. XII, disponía el párrafo segundo del art. 496 (dentro de las amenazas y coacciones): Incurrirán en las penas de arresto mayor en su grado máximo y multa de 20.000 a 200.000 pesetas los que actuando con violencia o intimidación, en grupo, o individualmente pero de acuerdo con otros, obliguen a otras personas a iniciar o continuar una huelga, paro o cierre patronal». 
Esta reforma no convenció y, desde el principio, fue duramente criticada por los partidos de la oposición ${ }^{12}$ y los sindicatos ${ }^{13}$ por considerar que se estaba criminalizando el comportamiento de los trabajadores. Esto a pesar de que este tipo supone suavizar las penas, pues antes de la reforma de 2015 las coacciones de los "piquetes» eran un supuesto agravado respecto de las coacciones del artículo $172 \mathrm{CP}$ (por ir dirigidas a impedir el ejercicio de un derecho fundamental). No obstante, observemos que sólo se aplicará el art. 315.3 en el caso de que la coacción se produzca en grupo o individualmente pero de acuerdo con otros $^{14}$. Caso contrario, se aplicará el artículo 172.1 Código penal ${ }^{15}$.

Recientemente se han presentado dos Proposiciones de Ley en las que se pide la derogación del apartado 3 del artículo 315 de Código penal. Han sido presentadas por el Grupo Parlamentario Socialista ${ }^{16}$ y por el Grupo Parlamentario Podemos-En Comú Podem-En Marea ${ }^{17}$. La derogación del delito previsto en el artículo 315.3 del Código penal nos llevaría a que las conductas que contempla volverían a ser consideradas coacciones comunes del artículo 172.118. Seguramente, estos

${ }^{12}$ El Grupo Parlamentario de IU, ICV-EUIA, CHA: La Izquierda Plural planteó la supresión del apartado 3 del art. 315 en el 'proyecto de reforma del Código penal de 2015 (enmienda núm. 172, en BOCG. Congreso Diputados, Serie A, núm. 662-2 de 10-12-2014). También lo propuso el Grupo Parlamentario Socialista, enmienda núm. 729. No prosperaron.

${ }^{13}$ El diario.es: «El Gobierno mantiene el artículo del Código Penal que castiga a los piquetes» «Los sindicatos reclaman la derogación de ese precepto por considerar que criminaliza un derecho fundamental». http://www.eldiario.es/economia/Gobierno-insiste-criminalizar-derecho-huelga_0_352764958.html. 20 Minutos (09/02/2016) Sindicatos piden derogar artículo 315.3 del Código Penal aunque reconocen que en Castilla y León se ha aplicado «con sentido común». http://www.20minutos.es/noticia/2668758/0/sindicatos-piden-derogar-articulo-315-3-codigo-penal-aunque-reconocen-que-cyl-se-ha-aplicado-con-sentido-comun/\#xtor=AD-15\&xts=467263

${ }^{14}$ Cabe plantearse, también, la posibilidad de que en algún caso concurriera el supuesto de grupo criminal enunciado en el art. 570. Ter.1 del Código penal, donde se dice: «A los efectos de este Código se entiende por grupo criminal la unión de más de dos personas que, sin reunir alguna o algunas de las características de la organización criminal definida en el artículo anterior, tenga por finalidad o por objeto la perpetración concertada de delitos», si bien es cierto que nos parecería algo excesivo para el caso que nos ocupa.

${ }^{15}$ Teniendo en cuenta que el texto legal hace referencia a «en grupo» $\mathrm{y}$ "otros», hay que entender que en la intervención o el acuerdo han de participar al menos tres personas, por lo que también sería de aplicación el artículo 172 en la actuación individual cuando el concierto sea entre dos, es decir, el que se interviene solo con otro más.

${ }^{16}$ Boletín Oficial de las Cortes Generales. Congreso de los Diputados. Serie B: Proposiciones de Ley, 10 de febrero de 2016.

17 Ídem, 16 de febrero de 2016.

${ }^{18}$ Art. 172.1 CP: «El que, sin estar legítimamente autorizado, impidiere a otro con violencia hacer lo que la ley no prohíbe, o le compeliere a efectuar lo que no quiere, sea justo o injusto, será castigado con la pena de prisión de seis meses a tres años o con multa de 12 a 24 meses, según la gravedad de la coacción o de los medios em- 
grupos parlamentarios han planteado dichas proposiciones de ley por considerar perjudicial para los trabajadores esta normativa, pero lo cierto es que después de la reforma de 2015, podría ser lo contrario, pues parece que la figura del art. 315.3 del Código Penal podría ser, en algunos supuestos, un tipo privilegiado respecto a las coacciones del art. 172.1.

En base a lo expuesto, entiendo que la derogación del apartado 3 del artículo 315 del Código penal sería oportuna. En este sentido creemos acertada la razón que se da en la exposición de motivos de la Proposición de Ley del Grupo Parlamentario Socialista, en la que se decía que «Si bien la Ley Orgánica 1/2015, de 30 de marzo, por la que se modifica la Ley Orgánica 1/1995, de 23 de noviembre, del Código penal, vino a mitigar la respuesta punitiva de la Ley, juzgamos que la misma no da una respuesta proporcionada, ni añade nada nuevo ni necesario atendiendo a la finalidad que la norma atendía. Es por ello que entendemos que el artículo 315.3 del Código penal debe desaparecer de nuestro ordenamiento punitivo, toda vez que el genérico delito de coacciones ya protege de manera adecuada la libertad de no hacer huelga». ${ }^{19}$

pleados. Cuando la coacción ejercida tuviera como objeto impedir el ejercicio de un derecho fundamental se le impondrán las penas en su mitad superior, salvo que el hecho tuviera señalada mayor pena en otro precepto de este Código.

${ }^{19}$ La Sentencia 23-09-2015 de la Audiencia Provincial de Asturias recoge en el primero de sus Fundamentos de Derecho: «La acción típica de este delito la constituye la conducta coactiva tendente a persuadir al trabajador no huelguista para que se adhiera a la huelga (antes de iniciarse o ya iniciada por otros), el ánimo tendencial de restringir la libertad de la persona se concreta en la parcela que constituye la libertad de trabajo, lo que lo diferencia del delito de coacciones ordinarias del artículo 172 del Código penal». 
